\title{
Article \\ Effectively Extracting Iceberg Freeboard Using Bi-Temporal Landsat-8 Panchromatic Image Shadows
}

\author{
Zhenfu Guan ${ }^{1}$, Xiao Cheng ${ }^{1,2,3,4}$, Yan Liu ${ }^{1,2,3, *}$, Teng Li $^{1}$, Baogang Zhang ${ }^{1,2,3(1)}$ and Zhitong Yu ${ }^{5}$ \\ 1 State Key Laboratory of Remote Sensing Science, College of Global Change and Earth System \\ Science (GCESS), Beijing Normal University, Beijing 100875, China; zhenfu_guan@mail.bnu.edu.cn (Z.G.); \\ chengxiao9@mail.sysu.edu.cn (X.C.); 201531490018@mail.bnu.edu.cn (T.L.); zhang_bob@bnu.edu.cn (B.Z.) \\ 2 Southern Marine Science and Engineering Guangdong Laboratory (Zhuhai), Zhuhai 519082, China \\ 3 University Corporation for Polar Research (UCPR), Beijing 100875, China \\ 4 School of Geospatial Engineering and Science, Sun Yat-sen University, Zhuhai 519082, China \\ 5 Qian Xuesen Laboratory of Space Technology, China Academy of Space Technology, Beijing 100094, China; \\ yuzhitong@qxslab.cn \\ * Correspondence: liuyan2013@bnu.edu.cn
}

Citation: Guan, Z.; Cheng, X.; Liu, Y.; Li, T.; Zhang, B.; Yu, Z. Effectively Extracting Iceberg Freeboard Using Bi-Temporal Landsat-8 Panchromatic Image Shadows. Remote Sens. 2021, 13, 430. https://doi.org/10.3390/ rs13030430

Academic Editor: Gareth Rees

Received: 7 December 2020

Accepted: 22 January 2021

Published: 26 January 2021

Publisher's Note: MDPI stays neutral with regard to jurisdictional claims in published maps and institutional affiliations.

Copyright: (C) 2021 by the authors. Licensee MDPI, Basel, Switzerland. This article is an open access article distributed under the terms and conditions of the Creative Commons Attribution (CC BY) license (https:// creativecommons.org/licenses/by/ $4.0 /)$.

\begin{abstract}
The freshwater flux from icebergs into the Southern Ocean plays an important role in the global climate through its impact on the deep-water formation. Large uncertainties exist in the ice volume transported by Southern Ocean icebergs due to the sparse spatial and temporal coverage of observations, especially observations of ice thickness. The iceberg freeboard is a critical geometric parameter for measuring the thickness of an iceberg and then estimating its volume. This study developed a new, highly efficient shadow-height method to precisely measure the freeboard of various icebergs surrounded by sea ice using Landsat-8 Operational Land Imager 15-m bi-temporal panchromatic image shadows at low-solar-elevation angles. We evaluated and validated shadow length precision according to bi-temporal measurements and comparison with the measurements from the unmanned aerial vehicle. We determined freeboard precision according to shadow length precision and solar elevation angle. In our case study area, 4832 available freeboard measuring points with shadow length precision better than 2 pixels covered 376 icebergs with sizes ranging from 0.002 to $0.7 \mathrm{~km}^{2}$ and with freeboard ranging from 2.3 to $83.4 \mathrm{~m}$. At the solar elevation angles of $5.2^{\circ}$, the freeboard precision of $64.1 \%$ data could reach $1 \mathrm{~m}$ and $86.9 \%$ could reach $2 \mathrm{~m}$. Our proposed method effectively filled in the data gap of existing freeboard measurement methods.
\end{abstract}

Keywords: iceberg; freeboard; shadow height; Antarctic; Landsat-8; optical remote sensing

\section{Introduction}

Icebergs are formed either by the calving of the seaward margins of floating glacier tongues or ice shelves or by the fragmentation of existing icebergs [1]. Iceberg calving represents up to half of the total loss of mass from Antarctic ice shelves [2-4]. Icebergs play an important role in the global freshwater cycle by transporting large amounts of fresh water away from the Antarctic coast and then distributing it into the upper few hundred meters of the open ocean $[5,6]$. The fresh-water flux generated by iceberg melting lowers the water density, and the icebergs cool their surroundings when they melt, increasing the water density. This effect is sufficient to alter the vertical density profile, affecting the characteristics of the pycnocline and the stability of the stratification of the upper ocean (e.g., [7]). Thus, icebergs are a mobile mediator of deep-water formation. Any increase in freshwater from iceberg discharge or ice shelf melting likely has a major impact on the ocean circulation [8-10]. For example, a large amount of fresh water added over the continental shelf could limit the production of Antarctic bottom water [11,12], while a more moderate addition of fresh water in the same location could instead only result in fresher Antarctic bottom water [13]. Thus, accurate estimates of iceberg volume are crucial 
to predicting the future of the Southern Ocean freshwater budget changes and its impact on the freshwater balance of the Southern Ocean.

The iceberg freeboard is an important geometric parameter for measuring the thickness of an iceberg and then estimating its volume, which is the difference between the surface elevation and the sea level elevation. The ice thickness can be indirectly estimated from the iceberg freeboard by assuming hydrostatic equilibrium [14]. Satellite laser and radar altimeter are widely used for freeboard extraction. Elevation profiles measured by the geoscience laser altimeter system (GLAS) carried on the Ice, Cloud, and Land Elevation Satellite (ICESat) have been used to study several large icebergs [15-17]. For example, Jansen et al. [15] observed the freeboard change of iceberg A-38B calved from the Ronne Ice Shelf. Wang et al. [17] measured the freeboard and ice thickness to estimate the mass of the disintegrated Mertz Ice Tongue. The radar altimeter is more widely used to estimate the freeboard of various icebergs [18-21]. For example, Tournadre et al. [18] proposed a method for estimating the annual mean total volume of ice in the Southern Ocean from 2002 to 2010, using the complete Jason- 1 archive. Then, Tournadre et al. [19] created a database of 5366 iceberg freeboards covering the period from 2002 to 2012 by analyzing high-rate waveforms of radar altimeters. In recent research on icebergs, CryoSat-2 Synthetic Aperture Interferometric Radar Altimeter (SIRAL) data has been used to help analyze the freeboard change of Iceberg A68, which broke away from the Larsen C Ice Shelf [20]. Tournadre et al. [22] detected and analyzed the area, freeboard, and volume of the relatively small iceberg $(<3 \mathrm{~km}$ in length) using three operation modes of the Cryosat-2 SIRAL.

The constraint of the altimeter method is that it only measures a profile of iceberg along the ground track. Mainly because of the large spacing between the altimeter satellite tracks, even those of the Cryosat-2 and ICESat-2, a follow-up mission of ICESat, cannot achieve the comprehensive observation of the freeboard of icebergs, especially small icebergs. Although they constitute only 3-4\% of the total ice volume, small icebergs represent a major part of the freshwater flux into the ocean [5]. Wesche and Dierking [23] and Li et al. [24] found that small icebergs with an area ranging from 0.06 to $10 \mathrm{~km}^{2}$ accounted for more than $90 \%$ of all Antarctic icebergs.

The optical image can also be used in iceberg freeboard estimation. The full freeboard of an iceberg can be estimated using the Digital Surface Model (DSM) generated using automatic image matching from optical stereo images. For example, Enderlin et al. [25] and Dryak et al. [26] used the DSM generated using WorldView satellite data to measure the freeboard and then the basal melting of icebergs. Li et al. [27] generated a DSM covering an iceberg area in Prydz Bay using Unmanned Aerial Vehicle (UAV) optical images. For Southern Ocean observation, this method has significant limitations in terms of data acquisition. The shadow-height method is an alternative way to measure the freeboard using optical images. Although shadows often are usually not desired for many remote-sensing applications, they can also provide useful hints about the features of the objects that cast those shadows [28]. Researchers have long used shadow information to estimate building height using high-resolution optical remote-sensing images [29-31]. Shadows on medium resolution satellite images can also be identified easily. This is especially true for images with low-solar-elevation angles in winter when iceberg shadows on sea ice are obvious and long, which makes it possible to accurately measure the iceberg freeboard. Few researchers, however, have extracted the shadows on satellite images and assessed their potential for polar iceberg freeboard applications. Li et al. [27] briefly discussed the relationship between iceberg shadows and their freeboard heights at lowsolar-elevation angles, but a systematic and comprehensive study of this method has not yet been conducted.

In this study, we used freely available Landsat- 8 satellite panchromatic images with solar elevation angles ranging from $5.4^{\circ}$ to $17.8^{\circ}$ to estimate the iceberg freeboard in Prydz Bay, Antarctica. Our methodology can be easily applied in other regions, thereby providing a valuable tool for generating widespread iceberg freshwater flux estimations. This paper is organized as follows. Section 2 introduces test and validation data. Section 3 describes the 
principles and procedures of the proposed model for iceberg shadow extraction, iceberg freeboard estimation and precision evaluation in detail. The experimental results and validation are presented in Sections 4-6 provides a discussion and conclusion and the direction of future work.

\section{Data and Case Study Area}

We used the Landsat-8 Operational Land Imager (OLI) 15-m resolution panchromatic images to extract the iceberg freeboard. The satellite is in a sun-synchronous, near-polar orbit, with a 16-day revisit period. We used Landsat-8 OLI Level 1T (Level 1 Terrain Corrected) GeoTIFF products. Those products were under WGS84 Antarctic Polar Stereographic projection and were post-processed through systematic radiometric and geometric corrections using the Level 1 Product Generation System [32] (obtained from http:/ /glovis.usgs.gov/). In the case study, we used four 15-m panchromatic images with solar elevation angles of $5.2^{\circ}$ on 29 August, $7.5^{\circ}$ on 7 September, $11.2^{\circ}$ on 16 September, and $17.5^{\circ}$ on 30 September 2016 (Table 1), for the bi-temporal iceberg freeboard measurements. We applied the bi-temporal shadow freeboard method across an $860-\mathrm{km}^{2}$ iceberg region near the Chinese Zhongshan Station, in Prydz Bay, East Antarctica. We identified more than 400 icebergs with sizes ranging from 0.001 to $0.7 \mathrm{~km}^{2}$ (Figure 1).

Table 1. Landsat-8 images used in this study.

\begin{tabular}{|c|c|c|c|c|}
\hline Scene ID & Path/Row & Acquisition Date and Time & Sun Elevation Angle $\left({ }^{\circ}\right)$ & Sun Azimuth Angle $\left({ }^{\circ}\right)$ \\
\hline LC81261082016242LGN01 & $126 / 108$ & $\begin{array}{c}29 \text { August } 2016 \\
03: 42: 32.6973890 \mathrm{Z}\end{array}$ & 5.4304 & 47.6402 \\
\hline LC81251092016251LGN01 & $125 / 109$ & $\begin{array}{l}7 \text { September } 2016 \\
03: 36: 48.4476370 Z\end{array}$ & 7.4940 & 49.2402 \\
\hline LC81241092016260LGN01 & $124 / 109$ & $\begin{array}{l}\text { 16 September } 2016 \\
\text { 03:30:38.9220280Z }\end{array}$ & 11.0083 & 49.3830 \\
\hline LC81261082016274LGN02 & $126 / 108$ & $\begin{array}{l}30 \text { September } 2016 \\
03: 42: 36.4227840 Z\end{array}$ & 17.8834 & 48.3589 \\
\hline
\end{tabular}

Three capsized icebergs near the case study area were observed by the Polar Hawk-III unmanned aerial vehicle (UAV) on 13 December 2016, collected in the Prydz Bay near the Chinese Zhongshan Station. The Polar Hawk-III is a fixed-wing UAV with an integrated remote sensing system. We used the freeboards derived from the $0.17-\mathrm{m}$ resolution DSM generated using the UAV data for the method validation. The UAV freeboard was calculated as the elevation difference between the iceberg and its surrounding sea ice. The DSM was generated by gridding the 3D model. The image obtained by the UAV was used to generate a high-quality sparse 3D point cloud after image key-point extraction and an initial alignment, and then, on-board global positioning system (GPS) and inertial measurement unit (IMU) information were employed to geo-reference our data [27]. The sparse clouds were manually filtered, followed by a densification using a multi-view stereopsis (MVS) algorithm to generate the high-quality dense point cloud. The dense point cloud was used to construct a DSM, from which a digital orthophoto map (DOM) was created with a $0.17-\mathrm{m}$ pixel resolution. The vertical precision of the DSM was about $1 \mathrm{~m}$ and the estimated freeboard precision was about $1.4 \mathrm{~m}$. A more in-depth description of the workflow and accuracy of these results can be found in Li et al. [27]. 


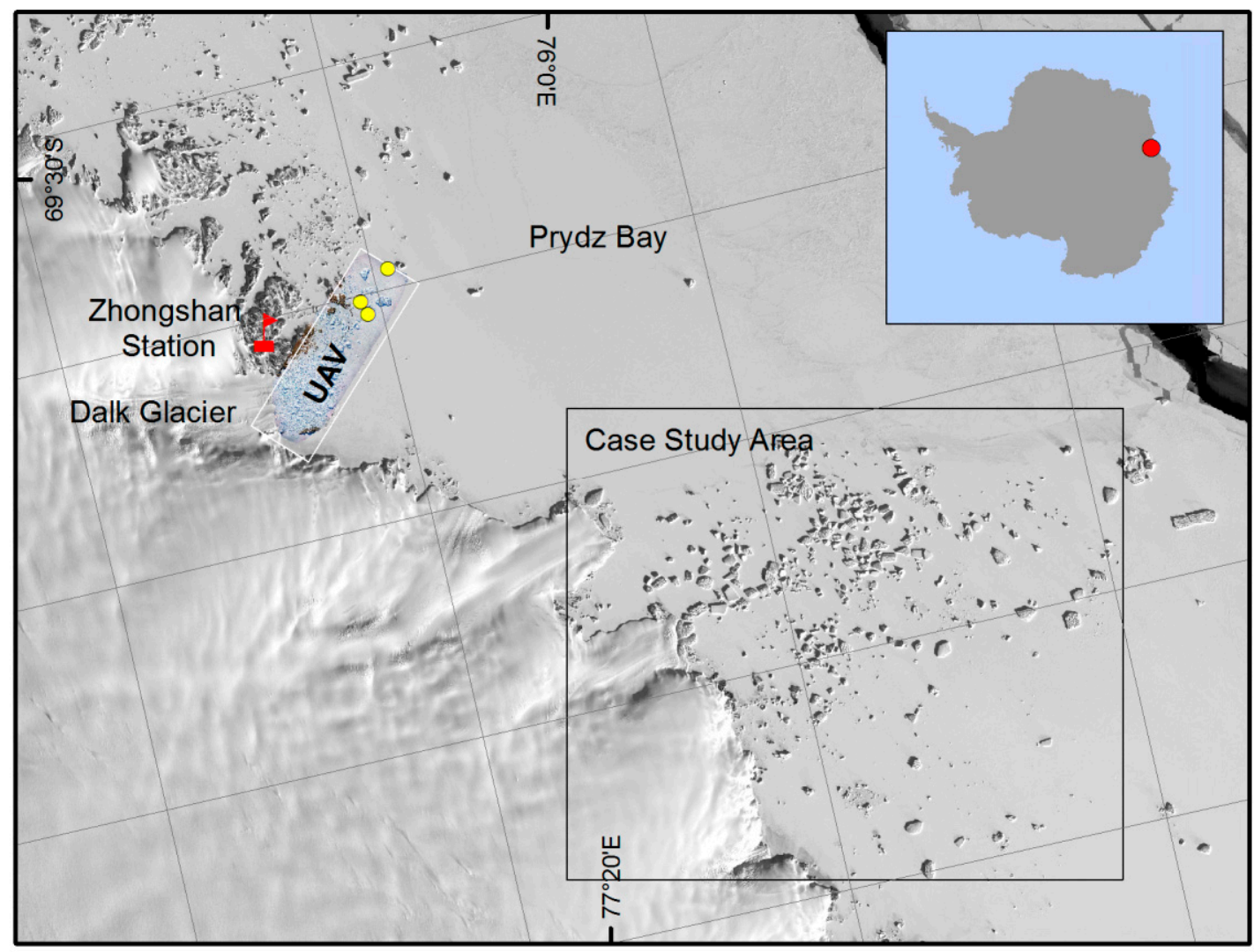

Figure 1. Locations of the case study area (black box) and the Unmanned Aerial Vehicle (UAV) data area (white box) overlaid on the Landsat-8 panchromatic image on 30 September 2016. The yellow points are the locations of the three UAV icebergs used in the validation.

\section{Methods}

\subsection{Iceberg Freeboard Measured by the Shadow-Height Method}

The freeboard of an iceberg surrounded by sea ice can be expressed as follows:

$$
H_{\text {iceberg }}=H_{\text {seaice }}+H \text {, }
$$

where $H_{\text {iceberg }}$ and $H_{\text {seaice }}$ are the freeboards of the iceberg and the sea ice, respectively; and $H$ is called the shadow freeboard of the iceberg (i.e., the difference between the elevations of the iceberg and the sea ice), which is the height of the iceberg measured using the shadow-height method.

If the shadow length $L$ of the iceberg on sea ice can be fully measured and the solar elevation angle $\theta$ causing the shadow is known, the shadow freeboard $H$ can be calculated using simple trigonometry, as follows:

$$
H=L \times \tan \theta,
$$

\subsection{Shadow Length Determination from Remote Sensing Image}

Shadows in remotely sensed imagery occur when objects totally or partially occlude the direct light coming from a source of illumination, which includes cast shadows (shadows cast on the ground, or on other objects, by high-rise objects), and self-shadows (the part of the object that is not illuminated by direction light). A cast shadow consists of two parts: the umbra and the penumbra. The umbra is created when direct light is completely blocked by an object, and the penumbra is created by something partially blocking the direct light $[33,34]$. The distance from the iceberg's peak point (called the shadow formation point, SFP) along the shaded area to the end point (called the shadow edge point, SEP) of 
the umbra is the extracting length required in the shadow-height method. The elevation and digital number (DN) profile of the iceberg along a beam of direct light is shown in Figure 2a,b.

(a)
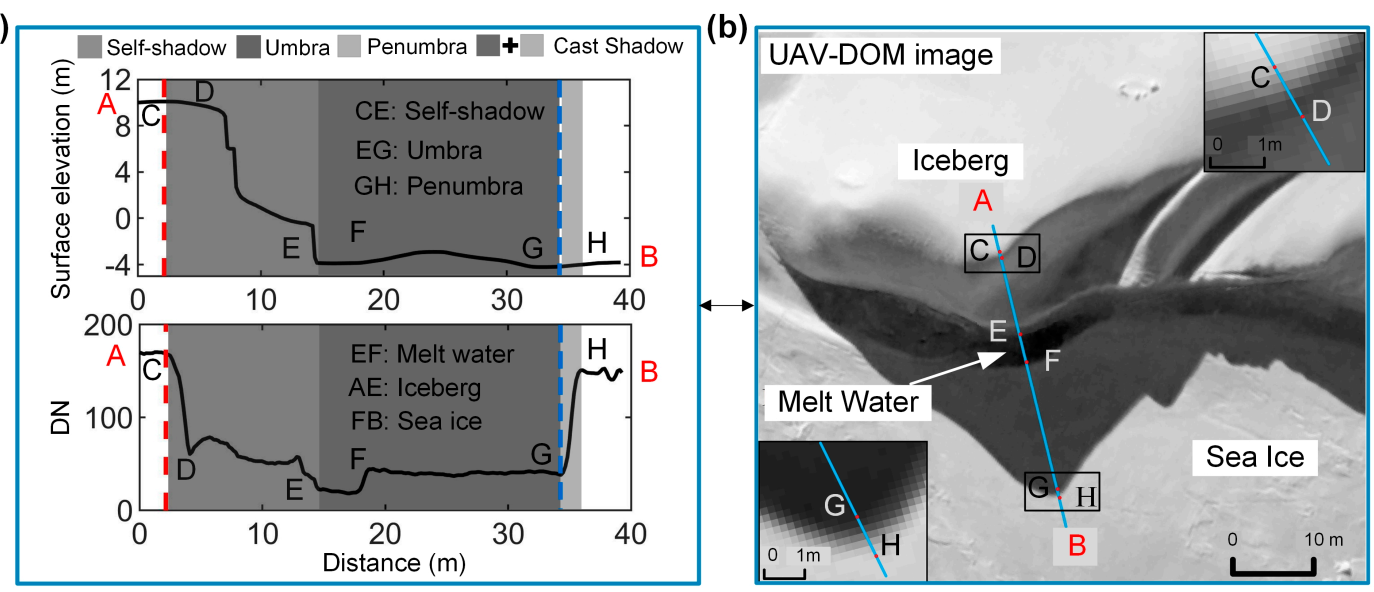

(c)

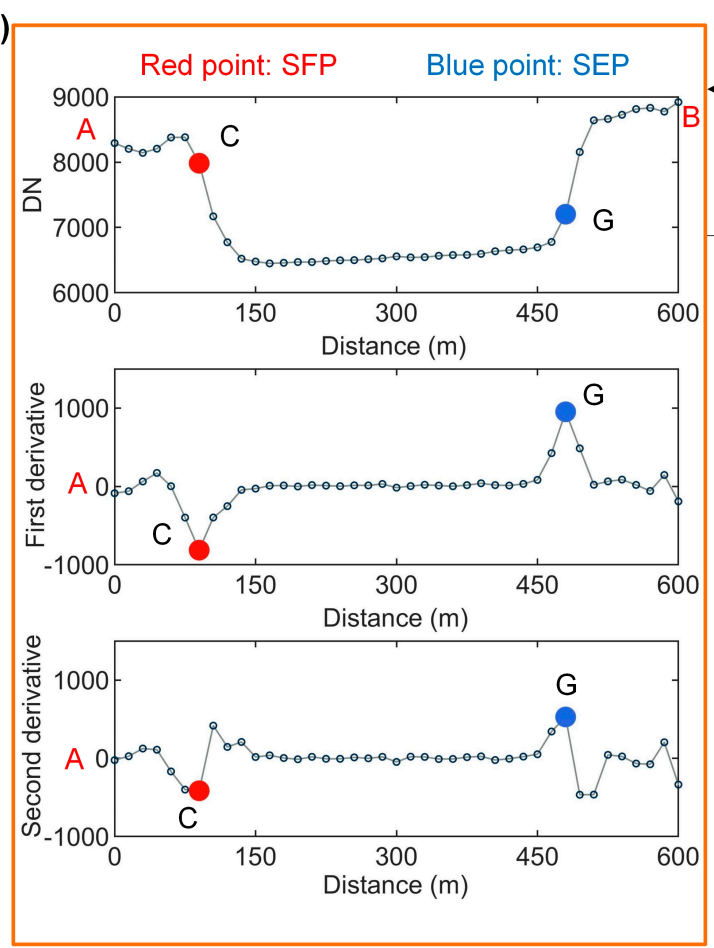

(d)

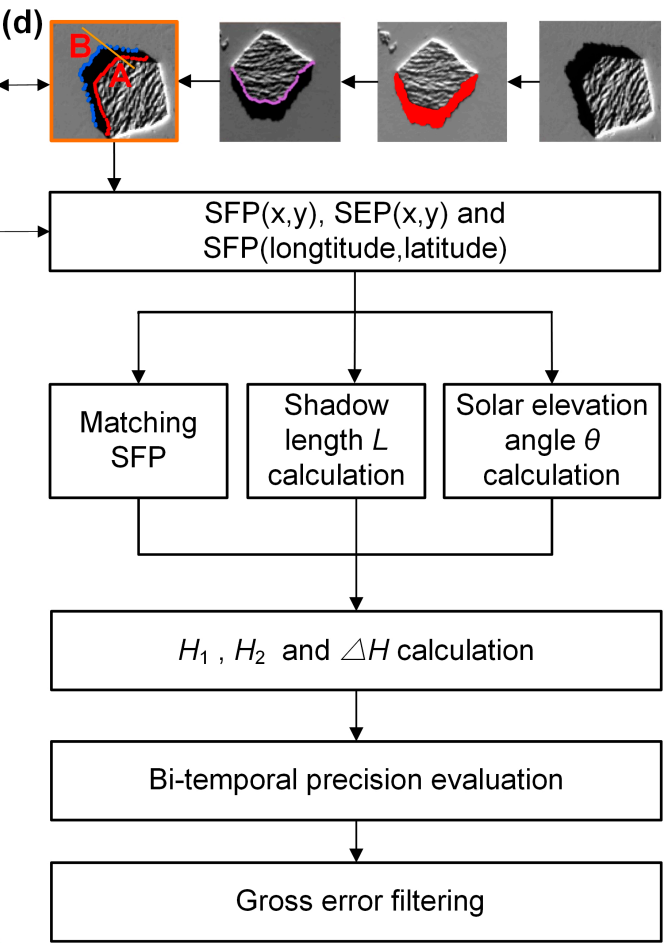

Figure 2. Flowchart of shadow extraction and iceberg freeboard estimation from bi-temporal Landsat-8 panchromatic remote-sensing images. (a) The elevation and grayscale profile of the blue line in (b), the red vertical dashed line is the grayscale value corresponding to the highest point of the iceberg, $\mathrm{DN}_{\mathrm{C}-\mathrm{D}}$ : Affected possibly by diffraction light; $\mathrm{DN} \mathrm{D}_{\mathrm{G}}$ : Objects' different reflection of scattering light. Dark gray areas are the umbra, light gray areas are the penumbra. (b) UAVDOM image. Combined with $(\mathbf{a}, \mathbf{b})$ it follows that: AE: Iceberg, EF: Meltwater, FB: Sea ice. (c) Location of the shadow formation points (SFPs) and the shadow edge points (SEPs) of the Landsat-8 image determined by our method, which is essentially the same as the position of the shadow determined in (a). The red point is the SFP, and the blue point is the SEP. (d) Iceberg freeboard estimation algorithm flowchart.

The gray DN-profile presents a U-shaped distribution showing that the shaded area is distinctly darker than the non-shaded area (Figure 2a,c), which is the basis for our shadow detection using the simple histogram thresholding method [35]. The DN-value sharply decreased after the SFP and the DN-value sharply increased after SEP, usually named as corner features [36], which provides the basis for precisely identifying the SFPs and 
the SEPs. Corner features are used to detect points where the curvature and the gradient magnitude are simultaneously high $[37,38]$. In particular, the curvature of the discrete point is approximately equal to its second-order derivative (as shown in Figure 2c). Thus, we combined the simple histogram threshing method and the corner features to accurately determine the iceberg shadow length.

\subsection{Solar Elevation Angle Calculation}

The Landsat- 8 metadata only provides the solar elevation and azimuth angles of the scene center point. The solar elevation and azimuth angle differences between the scene upper left corner and the scene lower right corner are up to 3 and 7 degrees, respectively. The freeboard measurement error caused by this would be more than several meters. Therefore, the solar elevation angle is calculated in each SFP to account for the differences in the accurate geographical coordinates of the SFPs, the date, and the time of the image acquisition. We used the Solar Position Algorithm (SPA) distributed by the National Renewable Energy Laboratory (NREL) Solar Radiation Research Laboratory $[39,40]$ to calculate the solar elevation and azimuth angles of the SFPs. We derived the solar elevation angle and the solar azimuth angle from the accurate geographical coordinates of the SFPs, the date, and the time of image acquisition. The SPA algorithm was used to calculate the solar elevation and azimuth angles in the period from the year -2000 to 6000 , with uncertainties of \pm 0.0003 degrees based on the date, time, and location [41], which contributes a freeboard measurement error of less than $0.001 \mathrm{~m}$. Thus, we could ignore the error in the measured height resulting from the solar elevation angle.

\subsection{Data Filtering by Bi-Temporal Evaluating Method}

The bi-temporal shadow freeboard measurement aims to evaluate the precision and to automatically filter out the gross error. With negligible iceberg movement in the two continuous phase images, we measured shadow freeboard $H$ of the matching SFP two times at different solar elevation angles. The difference between the two freeboard measurements, $\Delta H$, is calculated as follows:

$$
\Delta H=H_{2}-H_{1},
$$

The combined standard uncertainty with correlated input quantities, $u_{\Delta H}$, is determined by the combined standard uncertainty of $H_{1}$ and $H_{2}, u_{H_{1}}$ and $u_{H_{2}}$, and the correlation coefficient between $\mathrm{H}_{1}$ and $\mathrm{H}_{2}, r\left(\mathrm{H}_{1}, \mathrm{H}_{2}\right)$.

$$
u_{\Delta H}=\sqrt{u_{H_{1}}^{2}+u_{H_{2}}^{2}-2 u_{H_{1}} \times u_{H_{2}} \times r\left(H_{1}, H_{2}\right)},
$$

Since we ignored the solar elevation angle error, $u_{H_{1}}$ and $u_{H_{2}}$ are determined by the shadow length uncertainty (i.e., shadow length precision) and by the solar elevation angle, as follows:

$$
\left\{\begin{array}{l}
u_{H_{1}}=\tan \theta_{1} \times u_{L_{1}} \\
u_{H_{2}}=\tan \theta_{2} \times u_{L_{2}}
\end{array}\right.
$$

When the solar azimuth angles are equal or very close to each other, it can be assumed that $u_{L_{1}}=u_{L_{2}}=u_{L}$. Then,

$$
u_{\Delta H}=\sqrt{\tan \theta_{1}^{2}+\tan \theta_{2}^{2}-2 \tan \theta_{1} \times \tan \theta_{2} \times r\left(H_{1}, H_{2}\right)} \times u_{L},
$$

For any given $u_{L}, u_{\Delta H}$ can be obtained by iterations under the assumption of initial $r\left(H_{1}, H_{2}\right)=1$ and $\Delta \bar{H}=0$. Then, we calculated the correlation between the probability distribution of the observed $\Delta H$ at the given interval and the modeled $\Delta H$ following a random normal distribution with a mean of $\Delta \bar{H}$ and a standard deviation $(\sigma)$ of the $u_{\Delta H}$ at a given interval in the interval of $\Delta \bar{H} \pm 2 u_{\Delta H}$ (hereinafter referred to as the P-correlation). The fixed $r\left(H_{1}, H_{2}\right)$ and $\Delta \bar{H}$ for subsequent precision evaluation were the iterative calculation 
results of $r\left(H_{1}, H_{2}\right)$ and $\Delta \bar{H}$ at the $u_{L}$, where the P-correlation coefficient reached the maximum.

Then, the measurement uncertainty of shadow length, $u_{L-\text { Observerd }}$, in the interval of $\Delta \bar{H} \pm 2 u_{\Delta H}$, is calculated as follows:

$$
u_{L-\text { Observed }}=\frac{\sigma(\Delta H)}{\sqrt{\tan \theta_{1}^{2}+\tan \theta_{2}^{2}-2 \tan \theta_{1} \times \tan \theta_{2} \times r\left(H_{1}, H_{2}\right)}},
$$

where $\sigma(\Delta H)$ is the $\sigma$ of the $\Delta H$. The expected uncertainty of shadow length, $u_{L-\text { Expected, }}$ is $0.88 \times u_{L}$, which is the $\sigma$ of the modeled normally distributed shadow length error in the interval of $\pm 2 u_{L}$. The relative difference between the $u_{L-\text { Observed }}$ and $u_{L-\text { Expected }}$ is as follows:

$$
\Delta u_{L-\text { Relative }}=\frac{u_{L-\text { Observed }}-u_{L-\text { Expected }}}{u_{L-\text { Expected }}},
$$

$u_{L-\text { Expected }}$ was considered to be acceptable when $\Delta u_{L-\text { Relative }}$ was less than 0.1 and the P-correlation coefficient was greater than 0.8 . Then, we selected the freeboard data with

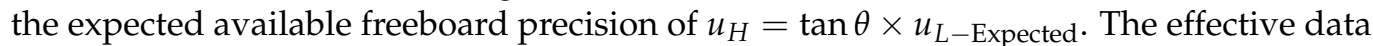
had a shadow length precision of better than 2 pixels $(30 \mathrm{~m})$, and the gross error without the effective interval was filtered out.

\subsection{The Process of Automatic Bi-Temporal Shadow Freeboard Measurement}

We developed an automatic process to measure the shadow freeboard $H$. The proposed process has six steps: (1) automatic extraction of the iceberg's shadow regions, filtering the shadows fully on icebergs and locating initial SFPs (SFP0s); (2) accurate determination of the locations of SFPs and SEPs using the corner features of interpolated DN-profile along the exact shadow direction of SFP0s (Figure 2c); (3) bi-temporal SFPs matching; (4) $H_{1}, H_{2}$, and $\Delta H$ calculation; (5) bi-temporal precision evaluation; and (6) gross error filtering. The general framework of the proposed method is shown in Figure 2d.

Shadow region detection, shadow filtering, and SFP0s acquisition. We automatically extracted the shadow regions from the Landsat- 8 panchromatic images using a histogram thresholding method. This method is based on the fact that the shaded areas are distinctly darker than the nonshaded areas. The shadow threshold is simply visually interpreted using the three-dimensional (3D) analyst tool. The full shadows on the icebergs were not our aim for iceberg freeboard measurement. These shadows could be filtered easily by the thresholds of the area and perimeter area ratio of the shaded areas. In this process, we also filtered out some of the shadows that were fully on the sea ice of the small icebergs with size less than $0.002 \mathrm{~km}^{2}$. Then, along the direction of the light, the first pixel of the shadow we obtained was the initial SFP (SFP0). The initial direction of the light is calculated based on the solar elevation and azimuth angles of the center point of the iceberg area. However, automating this process is complicated. If we redirect the shadow to the south of the image (e.g., parallel to the y-axis in the image coordinate system, as shown in Figure 2d) through rotation, automatically obtaining the SFP0 becomes easy. Thus, first we rotated the original image to redirect the shadow to the south of the image. To avoid losing the coordinate information, we rotated the original $x, y$ coordinate images. The Landsat- 8 Level 1T image products for Antarctica are defined in the Polar Stereographic Projection with $-71^{\circ} \mathrm{S}$ standard latitude to reduce the area distortion in the polar regions [42]. The image rotation angle is $\gamma=360-\alpha-\beta$, where $\alpha$ is the solar azimuth angle and $\beta$ is the longitude at the center of the iceberg region. Then, we automatically determined the initial SFP0s and SEP0s for the shadow length calculation as the first and end pixels of the shadow regions from the north to south of the rotated binary shadow image and obtained their $\mathrm{x}, \mathrm{y}$ coordinates from the rotated $\mathrm{x}, \mathrm{y}$ coordinate images.

Accurate determination of the SFPS and SEPS. To further accurately determine the SFPs and SEPs, we interpolated the DN-profile of the shaded area with a step length of 10-m and their neighboring nonshaded areas crossing every SFP0 along the shadow orientation. 
We accurately determined the shadow orientation using the SFP0's longitude and the solar azimuth angle that we derived from the extracted geographical coordinates of the SFP0s using the NREL's SPA. The angle between the direction of the shadow's orientation and the y-axis direction used to obtain the SFP0's DN-profile was calculated as follows:

$$
\delta_{i}=180-\alpha_{i}-\beta_{i},
$$

where $\alpha_{i}$ is the solar azimuth angle of the SFP0s, and $\beta_{i}$ is the longitude of the SFP0s. Thus, the purpose of the image rotation was to obtain the initial SFP0 and its corresponding shadow direction. Then, the accurate SFPs and SEPs were extracted using the corner features (Figure 2c).

Bi-temporal SFPs matching. We determined the two bi-temporal SFPs as the bi-temporal matching SFPs when the distance between them was less than the threshold of $15-\mathrm{m}$.

$H_{1}, H_{2}$, and $\Delta H$ calculation. According to the accurate location of the matching SFPs and their related SEPs, we calculated their shadow lengths, the solar elevation angles of the SFPs, and the single-shadow heights of $H_{1}$ and $H_{2} . \Delta H$ is the difference between $H_{1}$ and $\mathrm{H}_{2}$.

Bi-temporal precision evaluation. We estimated the shadow length precision and calculated the freeboard precision according to the method described in Section 3.4.

Gross error filtering. We filtered out the gross error using the expected shadow length precision.

\section{Shadow Freeboard Extracting Results}

We identified a total of 4824 SFPs with effective shadow freeboards using the bitemporal image shadows on August 29 and on September 30 (Figure 3a). We identified 376 icebergs ranging in size from 0.002 to $0.7 \mathrm{~km}^{2}$ with effective freeboards ranging from 2.3 to $83.4 \mathrm{~m}$, with a mean of $39.9 \mathrm{~m}$ and a $\sigma$ of $13.1 \mathrm{~m}$. The effective freeboard measurements covered different shapes of icebergs, such as the tabular, blocky, wedge, and pinnacle icebergs (Figure 3c). The tabular and wedge icebergs had a considerable number of available freeboard measurements. Visual interpretation indicated that the detected shadow vectors matched well with the image shadows (Figure $3 b, c)$. We effectively filtered out incomplete shadow vectors caused by neighboring icebergs and wrong shadow vectors caused by the inaccurate determination of SFPs and SEPs (Figure 4). We determined freeboard precision of the effective freeboards of $H_{8 / 29}$ ranging from $0.9 \mathrm{~m}$ to $2.7 \mathrm{~m}$ according to shadow length precision from 10 to $30 \mathrm{~m}$ and solar elevation angle of $5.2^{\circ}$. The freeboard precision of $86.9 \%$ data reached $2 \mathrm{~m}$, and $64.1 \%$ reached $1 \mathrm{~m}$. 


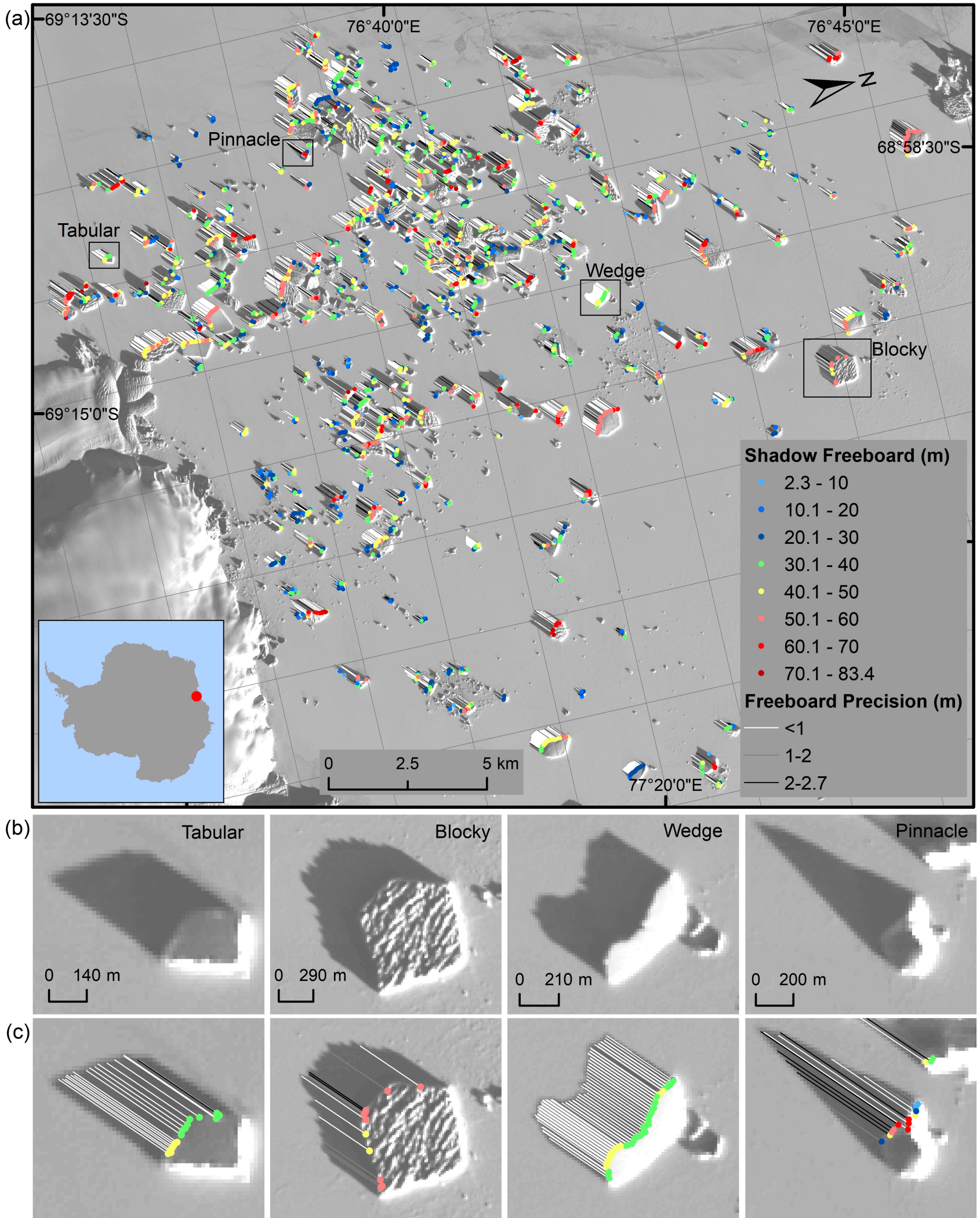

Figure 3. (a) Freeboards of $H_{8 / 29}$ with different precision in the case study area. The colored points show the freeboards of the SFPs of the different magnitudes. The colored lines are the shadow length line vectors from the SFPs, and the different colors indicate different freeboard precision of the SFPs. (b) Landsat-8 panchromatic shadow images on 29 August 2016 of the tabular, blocky, wedge, and pinnacle icebergs. (c) Effective freeboards with the precision of the tabular, blocky, wedge, and pinnacle icebergs. 


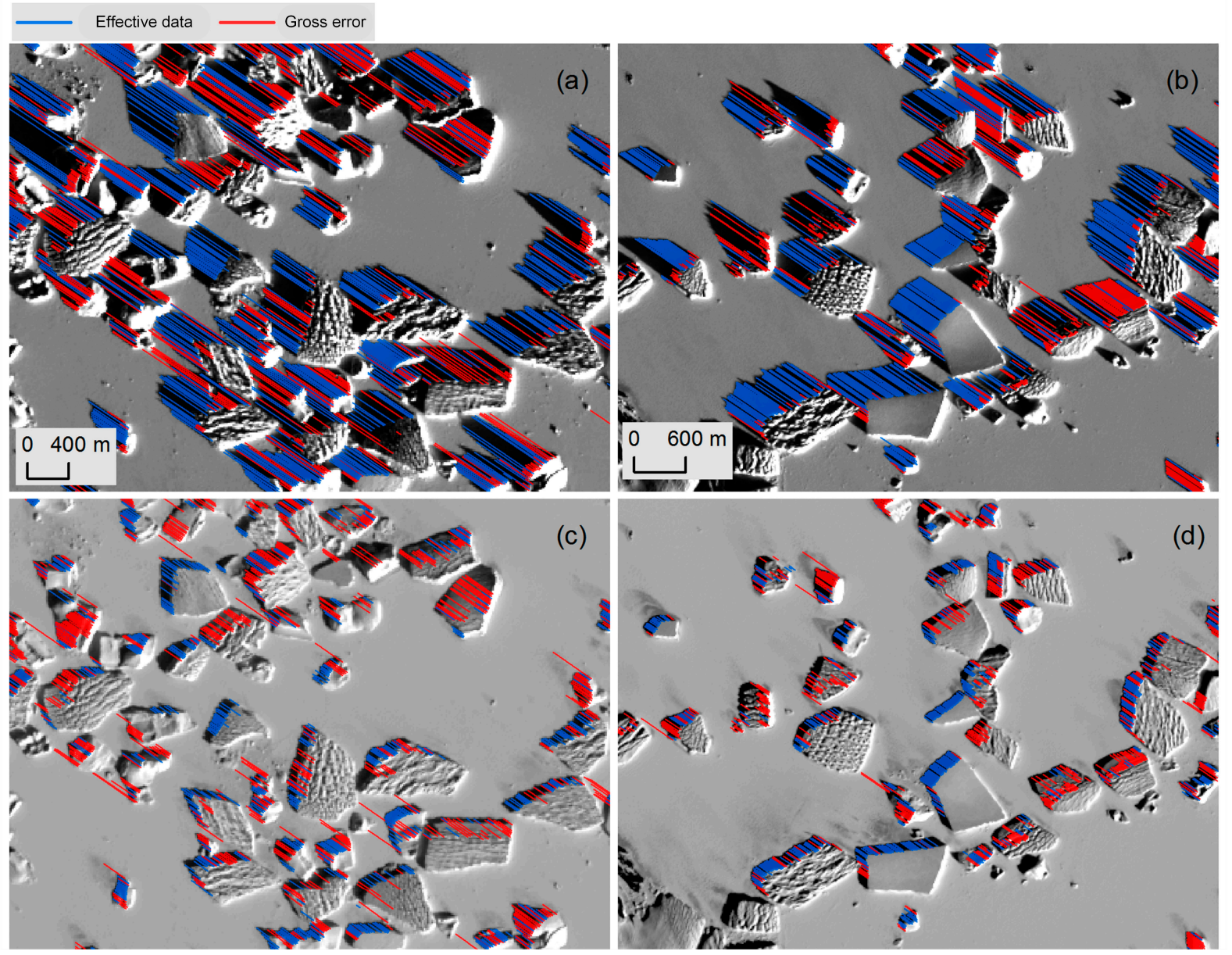

Figure 4. Gross error filtering of $H_{9 / 30}-H_{8 / 29}$. Distribution of the effective shadow vectors (blue lines) and the bad shadow vectors (red lines) overlaid on the images taken on (a,b) 29 August 2016, and (c,d) 30 September 2016.

\section{Validation}

In the study area, we obtained 9294 pairs of $H_{9 / 16}-H_{8 / 29}, 8670$ pairs of $H_{9 / 30}-H_{8 / 29}$, and 9218 pairs of $H_{9 / 30}-H_{9 / 16}$ bi-temporal matching SFPs, and 6313 tri-temporal matching SFPs from the single shadow freeboard measurements of $H_{8 / 29}, H_{9 / 16}$, and $H_{9 / 30}$, respectively. The solar elevation angles of the $H_{8 / 29}, H_{9 / 16}$, and $H_{9 / 30}$ were $5.17 \pm 0.05^{\circ}$, $11.16 \pm 0.05^{\circ}$, and $17.50 \pm 0.05^{\circ}$, respectively. Their solar azimuth angles were $47.6 \pm 0.05^{\circ}$, $49.24 \pm 0.05^{\circ}$, and $48.36 \pm 0.05^{\circ}$, respectively, which were so similar that we could ignore the shadow length precision differences among $H_{8 / 29}, H_{9 / 16}$, and $H_{9 / 30}$.

Our test showed that the best fits of the P-correlations between the observed $\Delta H_{9 / 16-8 / 29}, \Delta H_{9 / 30-8 / 29}$, and $\Delta H_{9 / 30-9 / 16}$ and a modeled normally distributed $\Delta H$ (Figure $5 \mathrm{a}-\mathrm{c}$ ) appeared at the $\mathrm{u}_{L-E x p e c t e d}$ of $21 \mathrm{~m}, 13 \mathrm{~m}$, and $22 \mathrm{~m}$, respectively. Their correspondence $r\left(H_{1}, H_{2}\right)$ values were $0.986,0.968$, and 0.976 , respectively. The bi-temporal measurements of the $H_{9 / 16}-H_{8 / 29}$ and $H_{9 / 30}-H_{9 / 16}$ had similar time intervals and their bi-temporal evaluations had more identical and consistent results. The $\Delta \bar{H}_{9 / 16-8 / 29}$, $\Delta \bar{H}_{9 / 30-8 / 29}$, and $\Delta \bar{H}_{9 / 30-9 / 16}$ are $0.60 \mathrm{~m}, 1.16 \mathrm{~m}$, and $0.92 \mathrm{~m}$, respectively, which indicated the system errors of the shadow length are $5.5 \mathrm{~m}, 5.0 \mathrm{~m}$, and $7.1 \mathrm{~m}$ (all less than half a pixel) rather than the freeboard change due to snowfall, the basal freezing of iceberg or the basal melting of the sea ice. This is because snowfall both increases the iceberg and sea ice elevation, which contribute little shadow to the freeboard of the iceberg. Such shadow freeboard changes due to basal freezing of the iceberg would cause sea ice breakage that we did not observe. The possible changes in the sea ice freeboard in 32 days is on the order of less than $0.1 \mathrm{~m}$. With known $\Delta \bar{H}$ and $r\left(H_{1}, H_{2}\right)$, we calculated the variations of the $u_{L-O b s e r v e d}$, 
$\Delta u_{L-\text { Relative }}$ and P-correlation coefficient with the $u_{L-\text { Expected }}$ (Figure $5 \mathrm{~d}-\mathrm{f}$ ). The analysis of variance (ANOVA) test results were consistent with the expectation that there were no significant differences $(p>0.05)$ among the three bi-temporal $u_{L-O b s e r v e d}$ or between any two when $u_{L-\text { Expected }}$ ranged from $0 \mathrm{~m}$ to $45 \mathrm{~m}$ at $1-\mathrm{m}$ intervals. These results demonstrated the effectiveness of the bi-temporal method for shadow length precision evaluation.
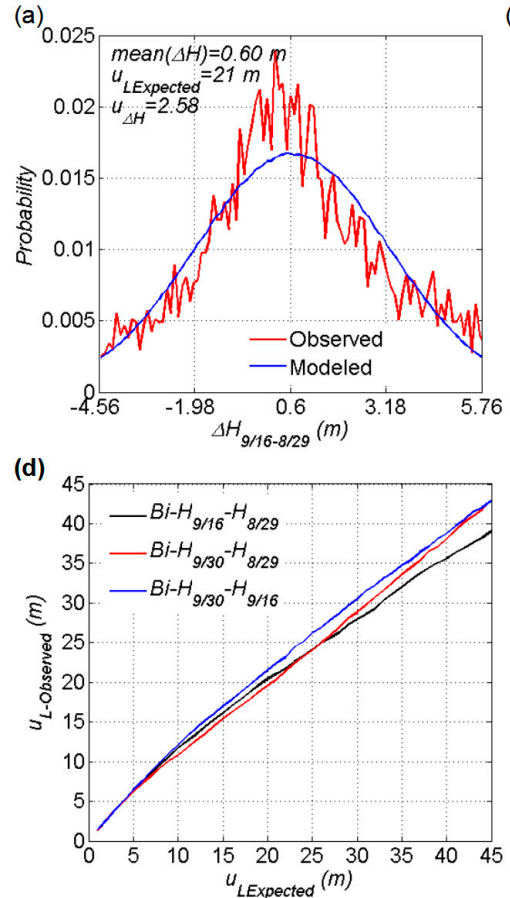

(g)

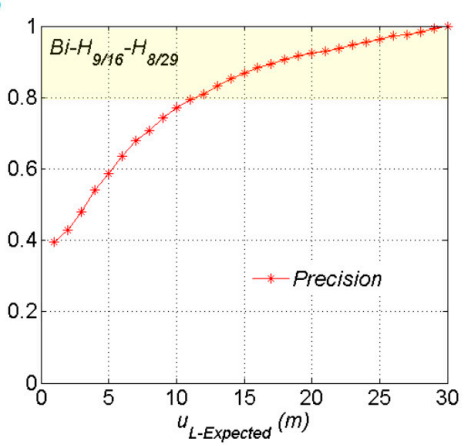

(b)

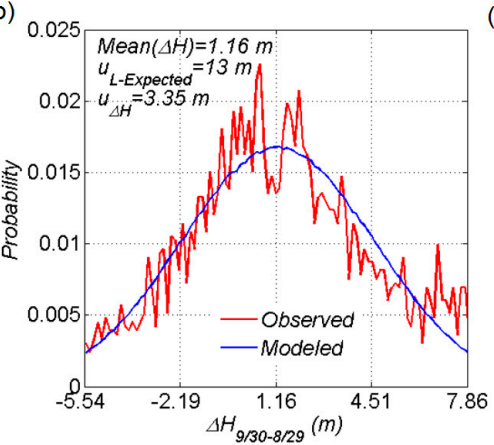

(e)

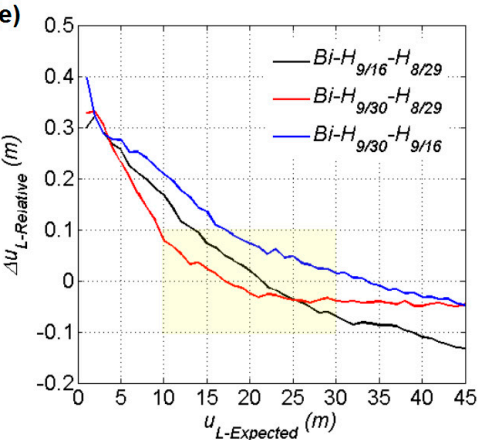

(h)

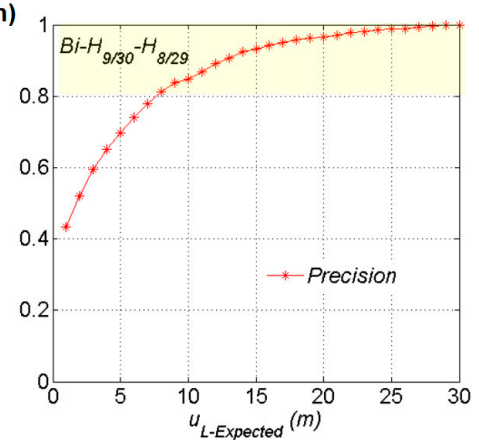

(c)

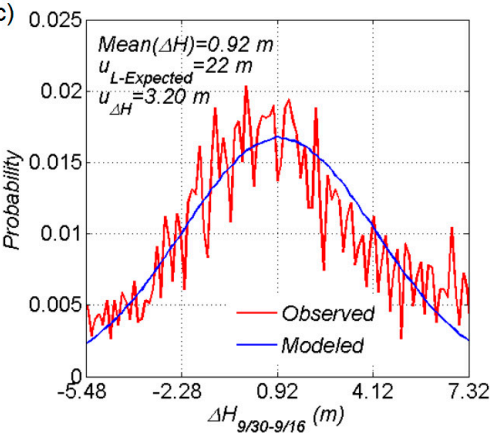

(f)

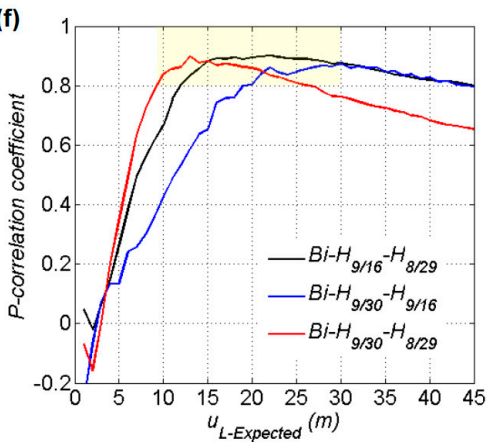

(i)

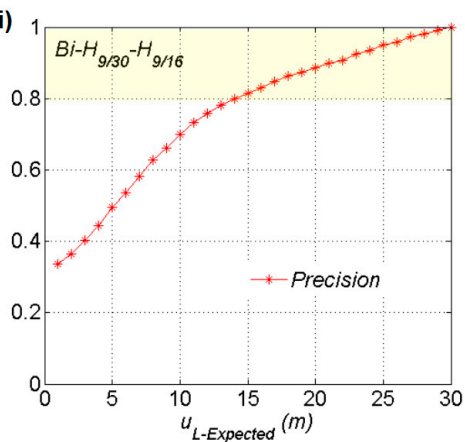

Figure 5. The probability distributions between the observed (a) $\Delta H_{9 / 16-8 / 29,}$, (b) $\Delta H_{9 / 30-8 / 29}$, and (c) $\Delta H_{9 / 30-9 / 16}$ and a modeled normal distributed $\Delta H$ with means of $\Delta \bar{H}$ and $1-\sigma$ of $u_{\Delta H}$ in the interval of $\Delta \bar{H} \pm 2 u_{\Delta H}$ at $0.04 \times u_{\Delta H}$ intervals. The variations of the (d) $u_{L-O b s e r v e d}$, the (e) absolute $\Delta u_{L-\text { Relative, }}$ and the (f) P-correlation coefficient with the $u_{L-E x p e c t e d}$ at 1-m intervals. The precision of the bi-evaluated shadow length precision of the (g) bi- $\mathrm{H}_{9 / 16}-\mathrm{H}_{8 / 29}$, (h) bi- $\mathrm{H}_{9 / 30}-\mathrm{H}_{8 / 29}$, and (i) bi- $H_{9 / 30}-H_{9 / 16}$.

Our required $u_{L-\text { Expected }}$ range should be less than $30 \mathrm{~m}$ (2 pixels), and the effective shadow precision range judged by the $\Delta u_{L-\text { Relative }}$ less than 0.1 was consistent with those judged by the P-correlation coefficient greater than 0.8 (Figure $5 \mathrm{e}, \mathrm{f}$ ). The effective $u_{L-E x p e c t e d}$ ranges of the bi $-H_{9 / 16}-H_{8 / 29}$, bi- $H_{9 / 30}-H_{8 / 29}$, and bi- $H_{9 / 30}-H_{9 / 16}$ were $14-30 \mathrm{~m}$, 10-26 m, and 19-30 m, which indicated that we could select available freeboard data with expected precision within these ranges. Furthermore, we tested the precision of our proposed evaluation method by cross-validation of the three bi-evaluations. The precision of one bi-evaluated set was calculated as $P=N_{u \mathrm{~L}} / U N_{u \mathrm{~L}}$, where the $N_{u \mathrm{~L}}$ was the number of one bi-evaluated set and $U N_{u \mathrm{~L}}$ was the number the union of the three bi-shadow evaluated sets. Excluding the gross error, there were 2728 of tri-temporal matching SFPs 
with $u_{L-\text { Expected }}$ better than $30 \mathrm{~m}$. As expected, these results showed that high-precision appeared in the effective ranges of shadow length precision (Figure $5 \mathrm{~g}-\mathrm{i}$ ).

To further validate freeboard precision, we compared the effective shadow freeboard $H_{9 / 7}$ and $H_{9 / 16}$ with the UAV freeboard of $H_{\mathrm{UAV} 12 / 13}$. The former Landsat- 8 freeboards had the expected precision of $2.1 \mathrm{~m}$ and $3.0 \mathrm{~m}$, whereas the latter had an estimated precision of $1.4 \mathrm{~m}$. We used the 51 effective matchings SFP pairs of $\mathrm{H}_{9 / 7}$ and $\mathrm{H}_{9 / 16}$ on the three UAVinvestigated icebergs for validation (Figure $6 \mathrm{a}, \mathrm{b}$ ). The locations of the SFPs agreed well with the iceberg peaks along with the light directions. The spatial resolution of the UAV image of $0.17-\mathrm{m}$ was about 100 times higher than the $15-\mathrm{m}$ Landsat- 8 panchromatic image. The average standard deviation of the $H_{\mathrm{UAV} 12 / 13}$ measurements within an SFP grid was up to $1.32 \mathrm{~m}(n=51)$. The shadow freeboards $H_{9 / 7}$ and $H_{9 / 16}$ were highly correlated with the $\bar{H}_{U A V 12 / 13}$ and the $\bar{H}_{U A V 12 / 13}+2 \sigma_{U A V 12 / 13}(\mathrm{r}>0.99)$ (Figure 7). The shadow freeboards $H_{9 / 7}$ and $H_{9 / 16}$ had better York's linear fits with errors [43] and a smaller basis with the $\bar{H}_{U A V 12 / 13}+2 \sigma_{U A V 12 / 13}$ (Figure $7 \mathrm{c}, \mathrm{d}$ ). These results indicated that the shadow freeboard better represented the peak profile within the area of the SFP grid. Thus, the precision of the shadow freeboards of $H_{9 / 7}$ and $H_{9 / 16}$ validated by UAV freeboards were $1.89 \mathrm{~m}$ and $2.53 \mathrm{~m}$, which were within the expected precision by the bi-temporal measurement.

(a)
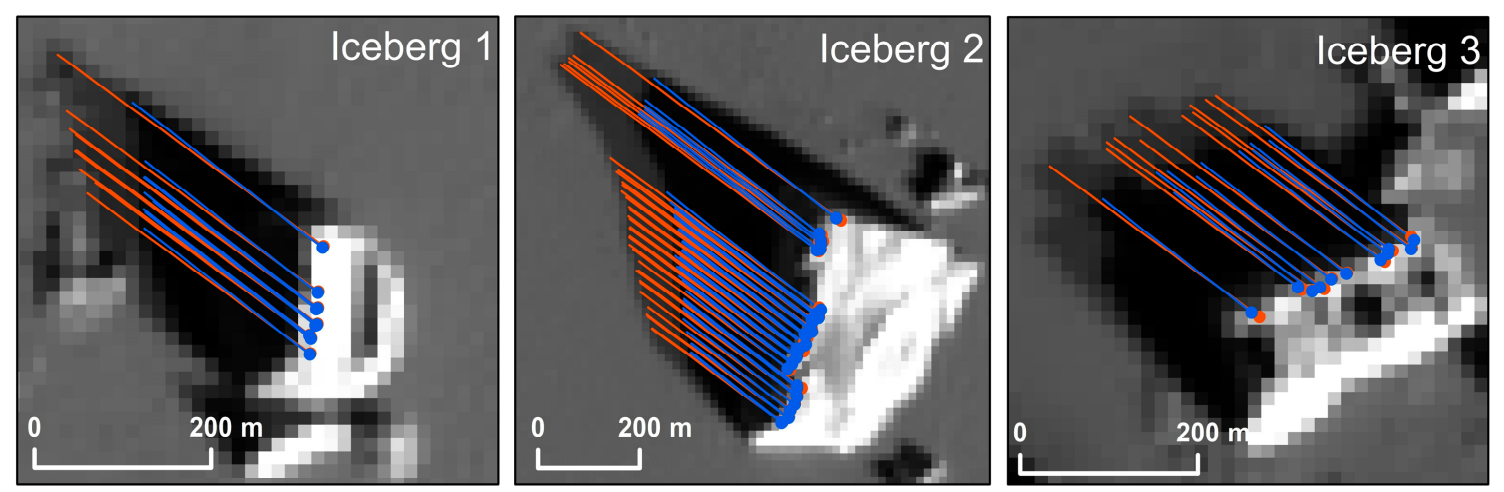

(b)
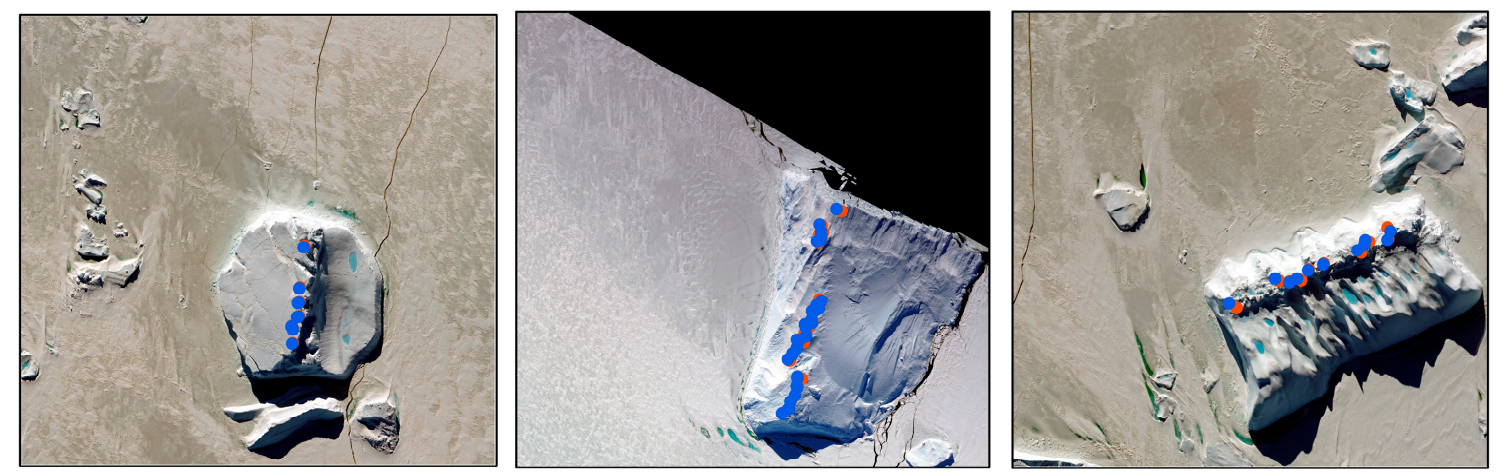

Figure 6. The three capsized icebergs on (a) the Landsat-8 15-m resolution Panchromatic overlaid images with 50\% transparency taken on 7 September, 2016, and 16 September, 2016; (b) the 0.17-m resolution UAV images on 13 December 2016. The blue and orange lines show the shadow length extraction results for the Landsat- 8 images taken on 7 September 2016 and 16 September 2016, respectively. The blue and orange dots show the iceberg shadow formation points extracted on 7 September 2016 and 16 September 2016, respectively. 

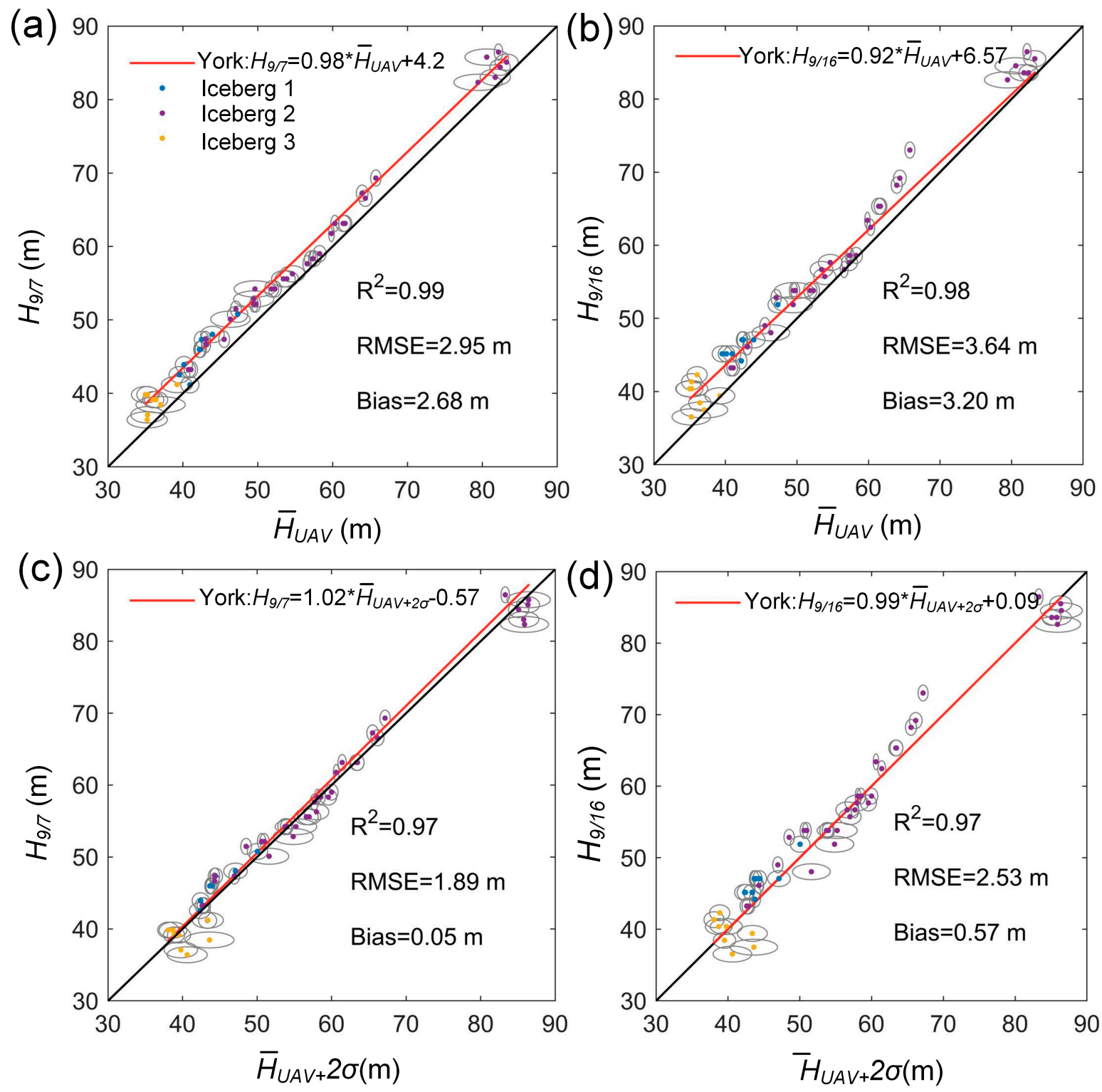

Figure 7. The comparison between the shadow freeboard and UAV freeboard, the (a) $H_{9 / 7}$ and $\bar{H}_{U A V 12 / 13}$, (b) $H_{9 / 16}$ and $\bar{H}_{U A V 12 / 13}$, the (c) $H_{9 / 7}$ and $\bar{H}_{U A V 12 / 13}+2 \sigma_{U A V 12 / 13}$, and the (d) $H_{9 / 16}$ and $\bar{H}_{U A V 12 / 13}+2 \sigma_{U A V 12 / 13}$. The red lines show the York's linear fit between the data. The fit considered the estimated precision of the shadow freeboard $H_{9 / 7}$ and $H_{9 / 16}$, the precision of the UAV freeboard, and the standard deviation of the $\bar{H}_{U A V 12 / 13}$. The black line is the 1:1 line.

\section{Discussion and Conclusions}

Our proposed method provided a general methodological framework for various iceberg freeboard extraction using freely available Landsat-8 OLI, 15-m bi-temporal panchromatic image shadows. This method has the advantage that it is simple to model, required less manual intervention, and has a considerably high precision.

The combination of the histogram thresholding method and the corner features of the shadow's DN-profile was able to break through the difficulties caused by the complex interactions of geometry, albedo, and illumination and accurately determined the iceberg shadow length. The automatic shadow length acquisition was easily achieved by redirecting the shadow to the south. We precisely estimated the shadow freeboard based on the previously noted precise shadow length extraction and the SPA's accurate solar elevation angle calculation. 
For many reasons, the full length of the iceberg shadow cannot always be obtained completely, for example, shadows can be obscured by the other icebergs, which leads to ineffective shadow freeboard measurement. Manually filtering the gross error can be time-consuming and laborious, especially for a large number of measurements. Our proposed bi-temporal evaluation method successfully evaluated the measurement precision and filtered out the gross error. Its effectiveness was tested and validated by generating the freeboard data of the icebergs in an area in Prydz Bay, East Antarctic, using the four Landsat-8 panchromatic images and the UAV freeboard data. The bi-evaluation method enabled us to obtain the system error of the shadow length measurement of this method, which is less than half a pixel. Furthermore, it enabled us to select available data with expected precision within the effective precision range. The effective precision range was dependent on the minimum solar elevation angle of the bi-temporal freeboard measurements and the time interval between the two measurements. We expect to select out higher precision data from the bi-temporal measurements with lower minimum solar elevation angle and longer time interval. The bi-temporal evaluation has a harmless disadvantage. According to Equation (6), the precision of the single shadow freeboard was more likely to be underestimated when there was little systematic error. This indicated that some effective data were filtered out as gross errors. Tri-temporal evaluation using three shadow freeboard measurements may be effective in avoiding this problem to some extent, but it faces the difficulty of data acquisition.

The freeboard changes of iceberg and sea ice had a rather small impact on the bitemporal shadow freeboard estimation and validation when the iceberg was trapped in sea ice from August to December. Tournadre et al. [19] ignored the iceberg freeboard change when the iceberg was trapped in sea ice and regarded the change of freeboard as a function of accumulated days of positive sea surface temperature. Most of the observed freeboard change of iceberg was due to melting [19]. Neither the cross validation using the bi-temporal Landsat- 8 freeboards nor the comparison between and the UAV freeboard and the Landsat-8 shadow freeboard showed a decrease in the freeboard over time, which indicates that the impact of iceberg melting can be ignored. The long-term sea ice thickness (including ridges) in the Southern Ocean has been reported to be $0.87 \pm 0.91 \mathrm{~m}$ [44]. Assuming that the ratio of the thickness of the ice below sea level to the freeboard of the sea ice (i.e., the thickness of ice plus snow above sea level) is 7 based on the mean ratio of those of the snow-free ice and the ridged ice are 9 and 5.1, respectively [44], the mean freeboard of the sea ice is $0.11 \pm 0.12 \mathrm{~m}$, which is relatively small compared to the freeboard of the iceberg and its measurement error obtained from the shadow height. Therefore, the impact of the freeboard change on the bi-temporal elevation and precision validation can be ignored. Notably, the shadow freeboard is not the full freeboard of iceberg and the freeboard of the sea ice is relatively small but cannot be ignored in the estimation of the freeboard of iceberg.

The DSM generated from high resolution optical images can be used to measure the full freeboard of the entire iceberg just as the UAV freeboard used in our validation. However, this method has significant limitations in terms of data acquisition at a continental scale. Like the constraint of the altimeter method, the shadow height method only measures a certain profile of the iceberg. Unlike the altimeter, which measures a profile of iceberg along the ground track, this method measures the highest profile along the direction of the sun's rays. For the average freeboard estimation of a tabular or block iceberg (Figure 3b), the errors could be offset by multiple measurements around the half-edge of the iceberg. For the average freeboard estimation of an iceberg with distinct elevation differences, such as a pinnacle or capsized iceberg, it was likely to be overestimated. Fortunately, the tabular or block icebergs accounted for the majority of the total Antarctic iceberg area. The disadvantage became an advantage in the iceberg freeboard change investigation. The high points of the iceberg were likely to be observed repeatedly by the shadow-height method even if the iceberg drifted or rotated, whereas the track profile rarely could be observed 
repeatedly by the altimeter [21]. This indicates that the shadow height method can be used to detect the freeboard change of an iceberg, and then its basal melting.

Further, unlike the altimeter, which only measures the icebergs covered by the orbit tracks, the optical image can measure nearly all of the icebergs with full shadow using the shadow height method. For example, the orbit spacing of the ICESat-2 satellite is about $6.6 \mathrm{~km}$ at $70^{\circ} \mathrm{S} / \mathrm{N}$. Only 76 icebergs could be tracked by all of the ICESat-2's repeated orbits in our case study area, while 376 icebergs could be effectively measured using the Landsat- 8 images (Figure 8). Furthermore, the other optical satellite images with higher resolution (such as the Sentinel-2 10-m visible images, and the WorldView-2 0.5-m images) could also be used to measure the freeboard of the icebergs using the shadow height method. Therefore, it can fill the significant gaps resulting from the insufficient altimeter coverage of the icebergs in the Southern Ocean. However, the shadow freeboard method depended on sea ice coverage and its precision depended on the solar elevation angle, which restricted its applicability. The optical remotely sensed data could be used in the shadow freeboard method, which was also affected by cloud cover. Thus, this method could not replace the altimeter method but provided a good supplementary means.

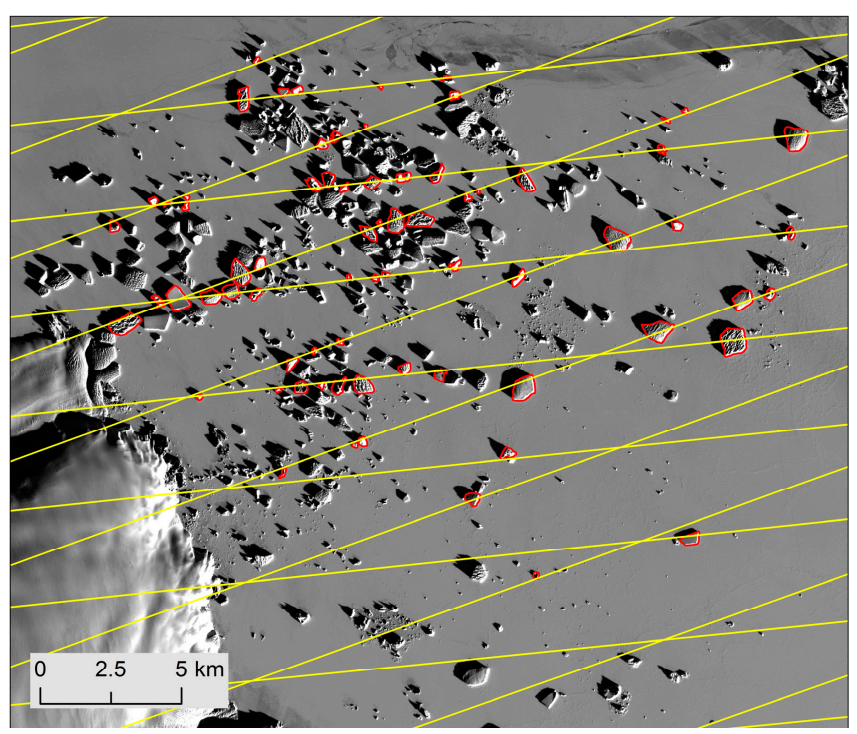

Figure 8. The 76 icebergs (red polygons) tracked by all the ICESat-2 repeated orbits (yellow lines) overlaid on the Landsat-8 image taken on 29 August 2016 in the study area.

The method presented in this study is a part of ongoing work to generate a highquality freeboard dataset of the various Antarctic icebergs. In the future, we plan to estimate basal melting of the icebergs using repeated shadow freeboard measurements.

Author Contributions: Z.G., Y.L. and X.C. conceived of, designed and conducted the experiment. Y.L. and Z.G. contributed to the research framework and helped develop the methodology. Y.L. and Z.G. performed the data analysis. Z.G., Y.L., T.L., Z.Y. and X.C. contributed to analyzing the results. Z.G., B.Z., T.L. and Z.Y. contributed to the data processing. All authors have read and agreed to the published version of the manuscript.

Funding: This research was funded by the National Natural Science Foundation of China (Grant No. 41925027), the National Key Research and Development Program of China (Grant No. 2016YFA0600103), and the Qian Xuesen Lab.-DFH Sat. Co. Joint Research and Development Fund.

Acknowledgments: We thank the United States Geological Survey (USGS) for providing the Landsat8 data (http://glovis.usgs.gov/), the UAV data created by ZHENFU GUAN have been deposited in https:/ / zenodo.org/record/4287772\#.X7x5LWgzaMo (doi:10.5281/zenodo.4287772).

Conflicts of Interest: The authors declare that they have no conflict of interest. 


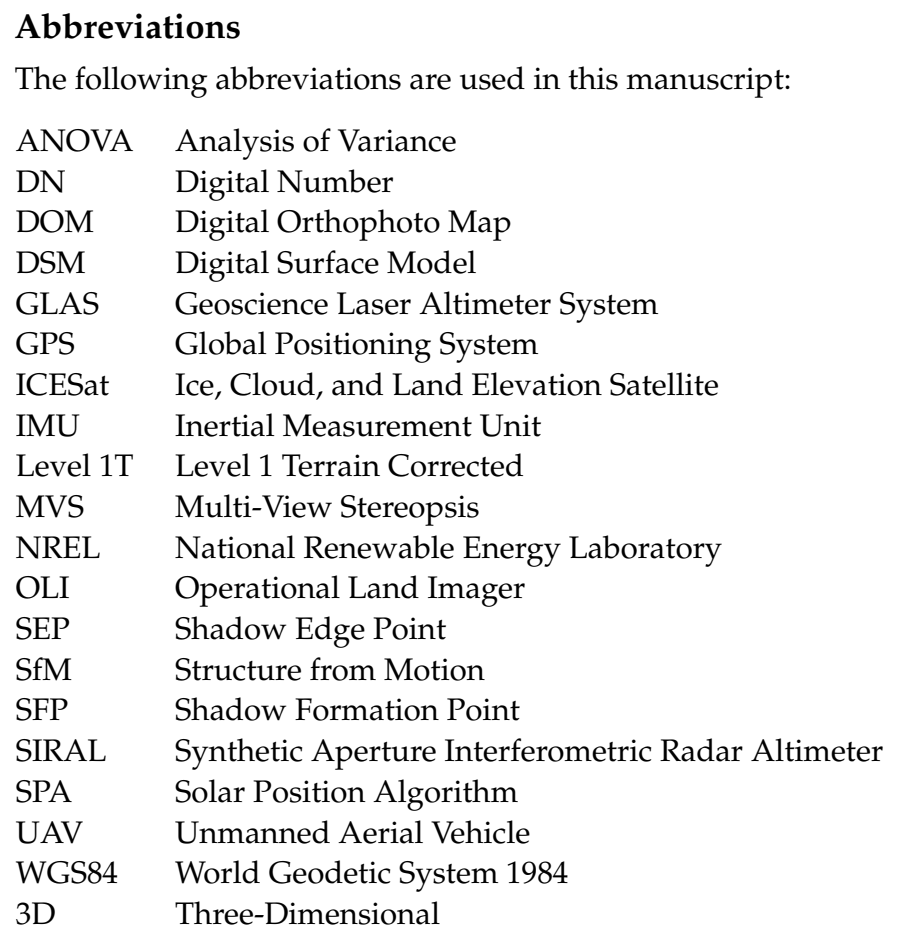

\section{References}

1. Benn, D.I.; Astrom, J.A. Calving glaciers and ice shelves. Adv. Phys. X 2018, 3, 1513819. [CrossRef]

2. Depoorter, M.A.; Bamber, J.; Griggs, J.; Lenaerts, J.T.; Ligtenberg, S.R.; van den Broeke, M.R.; Moholdt, G. Calving fluxes and basal melt rates of Antarctic ice shelves. Nature 2013, 502, 89-92. [CrossRef] [PubMed]

3. Rignot, E.; Jacobs, S.; Mouginot, J.; Scheuchl, B. Ice-shelf melting around Antarctica. Science 2013, 341, 266-270. [CrossRef] [PubMed]

4. Liu, Y.; Moore, J.C.; Cheng, X.; Gladstone, R.M.; Bassis, J.N.; Liu, H.; Wen, J.; Hui, F. Ocean-driven thinning enhances iceberg calving and retreat of Antarctic ice shelves. Proc. Natl. Acad. Sci. USA 2015, 112, 3263-3268. [CrossRef]

5. Tournadre, J.; Bouhier, N.; Girard-Ardhuin, F.; Remy, F. Antarctic icebergs distributions 1992-2014. J. Geophys. Res. 2016, 121, 327-349. [CrossRef]

6. England, M.R.; Wagner, T.J.W.; Eisenman, I. Modeling the breakup of tabular icebergs. Sci. Adv. 2020, 6, eabd1273. [CrossRef]

7. Gladstone, R.M.; Bigg, G.R.; Nicholls, K.W. Iceberg trajectory modeling and meltwater injection in the Southern Ocean. J. Geophys. Res. 2001, 106, 19903-19915. [CrossRef]

8. Silva, T.; Bigg, G.; Nicholls, K. Contribution of giant icebergs to the Southern Ocean freshwater flux. J. Geophys. Res. 2006, 111 [CrossRef]

9. Jongma, J.I.; Driesschaert, E.; Fichefet, T.; Goosse, H.; Renssen, H. The effect of dynamic-thermodynamic icebergs on the Southern Ocean climate in a three-dimensional model. Ocean Modell. 2009, 26, 104-113. [CrossRef]

10. Martin, T.; Adcroft, A. Parameterizing the fresh-water flux from land ice to ocean with interactive icebergs in a coupled climate model. Ocean Modell. 2010, 34, 111-124. [CrossRef]

11. Lago, V.; England, M.H. Projected Slowdown of Antarctic Bottom Water Formation in Response to Amplified Meltwater Contributions. J. Clim. 2019, 32, 6319-6335. [CrossRef]

12. Marsland, S.J.; Wolff, J.O. On the sensitivity of Southern Ocean sea ice to the surface freshwater flux: A model study. J. Geophys. Res. 2001, 106, 2723-2741. [CrossRef]

13. Menezes, V.V.; Macdonald, A.M.; Schatzman, C. Accelerated freshening of Antarctic Bottom Water over the last decade in the Southern Indian Ocean. Sci. Adv. 2017, 3, e1601426. [CrossRef] [PubMed]

14. Wang, X.; Cheng, X.; Gong, P.; Huang, H.; Li, Z.; Li, X. Earth science applications of ICESat/GLAS: A review. Int. J. Remote Sens. 2011, 32, 8837-8864. [CrossRef]

15. Jansen, D.; Schodlok, M.; Rack, W. Basal melting of A-38B: A physical model constrained by satellite observations. Remote Sens. Environ. 2007, 111, 195-203. [CrossRef]

16. Scambos, T.; Sergienko, O.; Sargent, A.; MacAyeal, D.; Fastook, J. ICESat profiles of tabular iceberg margins and iceberg breakup at low latitudes. Geophys. Res. Lett. 2005, 32. [CrossRef]

17. Wang, X.; Cheng, X.; Gong, P.; Shum, C.; Holland, D.M.; Li, X. Freeboard and mass extraction of the disintegrated Mertz Ice Tongue with remote sensing and altimetry data. Remote Sens. Environ. 2014, 144, 1-10. [CrossRef]

18. Tournadre, J.; Girard-Ardhuin, F.; Legrésy, B. Antarctic icebergs distributions, 2002-2010. J. Geophys. Res. 2012, 117. [CrossRef] 
19. Tournadre, J.; Bouhier, N.; Girard-Ardhuin, F.; Rémy, F. Large icebergs characteristics from altimeter waveforms analysis. J. Geophys. Res. 2015, 120, 1954-1974. [CrossRef]

20. Han, H.; Lee, S.; Kim, J.-I.; Kim, S.H.; Kim, H.-c. Changes in a giant iceberg created from the collapse of the larsen c ice shelf, Antarctic Peninsula, derived from Sentinel-1 and CryoSat-2 data. Remote Sens. 2019, 11, 404. [CrossRef]

21. Li, T.; Shokr, M.; Liu, Y.; Cheng, X.; Li, T.; Wang, F.; Hui, F. Monitoring the tabular icebergs C28A and C28B calved from the Mertz Ice Tongue using radar remote sensing data. Remote Sens. Environ. 2018, 216, 615-625. [CrossRef]

22. Tournadre, J.; Bouhier, N.; Boy, F.; Dinardo, S. Detection of iceberg using Delay Doppler and interferometric Cryosat-2 altimeter data. Remote Sens. Environ. 2018, 212, 134-147. [CrossRef]

23. Wesche, C.; Dierking, W. Near-coastal circum-Antarctic iceberg size distributions determined from Synthetic Aperture Radar images. Remote Sens. Environ. 2015, 156, 561-569. [CrossRef]

24. Li, T.; Cheng, X.; Guan, Z.; Liu, Y. Investigation of Antarctic icebergs based on SAR images. J. Nanjing Univ. Inform. Sci. Technol. Nat. Sci. Ed. 2020, 12, 231-235. [CrossRef]

25. Enderlin, E.M.; Carrigan, C.J.; Kochtitzky, W.H.; Cuadros, A.; Moon, T.; Hamilton, G.S. Greenland iceberg melt variability from high-resolution satellite observations. Cryosphere 2018, 12, 565. [CrossRef]

26. Dryak, M.C.; Enderlin, E.M. Analysis of Antarctic Peninsula glacier frontal ablation rates with respect to iceberg melt-inferred variability in ocean conditions. J. Glaciol. 2020, 66, 457-470. [CrossRef]

27. Li, T.; Zhang, B.; Cheng, X.; Westoby, M.J.; Li, Z.; Ma, C.; Hui, F.; Shokr, M.; Liu, Y.; Chen, Z.; et al. Resolving fine-scale surface features on polar sea ice: A first assessment of UAS photogrammetry without ground control. Remote Sens. 2019, 11, 784. [CrossRef]

28. Shao, Y.; Taff, G.N.; Walsh, S.J. Shadow detection and building-height estimation using IKONOS data. Int. J. Remote Sens. 2011, 32, 6929-6944. [CrossRef]

29. Irvin, R.B.; McKeown, D.M. Methods for exploiting the relationship between buildings and their shadows in aerial imagery. IEEE Trans. Syst. Man Cybern. 1989, 19, 1564-1575. [CrossRef]

30. Shettigara, V.; Sumerling, G. Height determination of extended objects using shadows in SPOT images. Photogramm. Eng. Remote Sens. 1998, 64, 35-43. [CrossRef]

31. Kadhim, N.; Mourshed, M. A shadow-overlapping algorithm for estimating building heights from VHR satellite images. IEEE GRSL 2017, 15, 8-12. [CrossRef]

32. Yang, K.; Smith, L.C. Internally drained catchments dominate supraglacial hydrology of the southwest Greenland Ice Sheet. J. Geophys. Res. 2016, 121, 1891-1910. [CrossRef]

33. Mamassian, P.; Knill, D.C.; Kersten, D. The perception of cast shadows. Trends Cogn. Sci. 1998, 2, 288-295. [CrossRef]

34. Yao, J.; Zhang, Z.M. Hierarchical shadow detection for color aerial images. Comput. Vis. Image Understand. 2006, 102, 60-69. [CrossRef]

35. Dos Anjos, A.; Shahbazkia, H.R. Bi-level image thresholding-A Fast Method. In Proceedings of the First International Conference on Bio-Inspired Systems and Signal Processing, Funchal, Portugal, 28-31 January 2008; pp. 70-76. [CrossRef]

36. Sirmacek, B.; Unsalan, C. Urban-area and building detection using SIFT keypoints and graph theory. IEEE Trans. Geosci. Remote Sens. 2009, 47, 1156-1167. [CrossRef]

37. Kitchen, L.; Rosenfeld, A. Gray-level corner detection. Patt. Recogn. Lett. 1982, 1, 95-102. [CrossRef]

38. Koenderink, J.J.; Richards, W. Two-dimensional curvature operators. J. Opt. Soc. Am. A 1988, 5, 1136-1141. [CrossRef]

39. Iqbal, M. An Introduction to Solar Radiation; Academic Press: Toronto, ON, Canada, 1983; pp. $23-25$.

40. Meeus, J. Astronomical Algorithms; Willmann-Bell, Inc.: Richmond, VA, USA, 1991; pp. 231-235.

41. Reda, I.; Andreas, A. Solar Position Algorithm for Solar Radiation Applications. Sol. Energy 2004, 76, 577-589. [CrossRef]

42. Roy, D.P.; Wulder, M.A.; Loveland, T.R.; Woodcock, C.E.; Allen, R.G.; Anderson, M.C.; Helder, D.; Irons, J.R.; Johnson, D.M.; Kennedy, R.; et al. Landsat-8: Science and product vision for terrestrial global change research. Remote Sens. Environ. 2014, 145, 154-172. [CrossRef]

43. York, D.; Evensen, N.; Martinez, M.; Delgado, J. Unified equations for the slope, intercept, and standard errors of the best straight line. Am. J. Phys. 2004, 72, 367-375. [CrossRef]

44. Worby, A.P.; Geiger, C.A.; Paget, M.J.; Van Woert, M.L.; Ackley, S.F.; DeLiberty, T.L. Thickness distribution of Antarctic sea ice. J. Geophys. Res. 2008, 113, C05S92. [CrossRef] 